\title{
FINKI Scholar, a Publications Database for Faculty of Computer Science and Engineering Scholars
}

\author{
Biljana Risteska Stojkoska, Hristijan Gjorshevski, and Elizabeta Mitreva
}

\begin{abstract}
The aim of this paper is to develop a web application where scholars of the Faculty of Computer Science and Engineering (FINKI) at the University of Ss. Cyril and Methodius can display and share their projects and publications. Visitors can view, search through, and filter the authors, projects and publications that can be added and edited by the administrators via the administrator panel. In this paper, we first explain the type of system we are building and go through similar existing systems explaining how they work and what they offer. Then, we go through the programming languages and technologies we decided to use to develop this web application. After that, the development phase follows, where we describe each of the features we implemented. In The Final Product section we finally show images where you can see how the web application works and what it looks like. We finish the paper with a conclusion, briefly summarizing what we have achieved.
\end{abstract}

Keywords - application, FINKI, Laravel, MySQL, publications, PHP, scholars, web.

\section{INTRODUCTION}

$\mathrm{F}$ INKI Scholar is a web application that allows users to store and retrieve authors, publications, and projects associated with the Faculty of Computer Science and Engineering. FINKI Scholar is developed using the Laravel PHP MVC framework, and a MySQL database on the backend. For the front-end, Blade is used as a templating engine, and Bootstrap is used as a CSS library for styling. jQuery is used for the numerous utility functions it provides. For displaying the data in a structured and organized manner, jQuery DataTables is used.

Before we go on with the technologies and development of the system we described, let us first take a look at the type of system we are building and explore similar existing solutions. In this paper, we first explain the type of system we are building and go through similar existing systems

Paper received May 01, 2020; revised May 09, 2021; accepted May 11, 2021. Date of publication July 31, 2021. The associate editor coordinating the review of this manuscript and approving it for publication was Prof. Miroslav Lutovac.

Prof. Biljana Risteska Stojkoska, PhD. Faculty of Computer Science and Engineering, USCM, Skopje, Macedonia, Ruger Boskovic, 16, 1000 Skopje, Republic of North Macedonia (e mail: biljana.stojkoska@finki.ukim.mk).

Hristijan Gjorshevski student. Faculty of Computer Science and Engineering, Ss. Cyril and Methodius University, Skopje, Republic of North Macedonia (phone: +389-923850; e mail: h.gjorshevski@gmail.com).

Prof. Elizabeta Mitreva, PhD. Faculty of Tourism and Business Logistics, Gevgelija "Goce Delčev" University, Štip, Republic of North Macedonia (e mail: elizabeta.mitreva@ugd.edu.mk). explaining how they work and what they offer. Then, we go through the programming languages and technologies we decided to use to develop this web application. After that, the development phase follows, where we describe each of the features we implemented. In The Final Product section we finally show images where you can see how the web application works and what it looks like. We finish the paper with a conclusion, briefly summarizing what we have achieved.

\section{ACADEMIC DATABASES AND SEARCH ENGINES}

Academic database and search engine are software designed to allow scientists or scholars part of an institution or organization to share their research with their peers and the rest of the world. Academic databases should allow registered users (researchers, scholars) or administrators to insert these data in the database and also allow the inserted data (authors, publications, projects) to be viewed by a group of people (the whole organization, or the general public). This way, the audience will be up to date with the scientific advancements of the researchers and will be able to use them in their own research. There are numerous popular existing academic databases, libraries and search engines. Some of them also act as an academic social network. Below we take a look at and analyze several of them.

\section{A. Academia.edu}

Academia.edu is a paid social networking platform for scholars. Academia is notorious among academics for spreading misleading spam emails, which wrongly state the recipient has been mentioned in research articles. According to McGill University scholar Jonathan Sterne, the basic idea of the site is good and it provides a useful service, but the question is whether Academia.edu can be trusted [1], [2], [3].

\section{B. Google Scholar}

Google Scholar is an openly accessible search engine based on the web that searches through the complete content or metadata of academic literature across a set of publishing formats and areas of research. According to the official Google Scholar documentation, its index includes most peer-reviewed online scholarly journals and books, conference papers, theses and dissertations, preprints, abstracts, reports of technical nature, and other scholarly literature, including court opinions and patents [3], [4]. Is Google Scholar limited just to academics? According to 
Business Insider, anyone with an Internet connection can connect to and access the Google Scholar search database [4], [5]. But does Google Scholar have any other impact on academia and research? According to Bar-Ilan Judit it does. He says that people do this out of laziness, they cite whatever papers the search engine ranks higher [6].

\section{Mendeley}

Mendeley is another one part of the populated market of academic social networks. According to its official website, Mendeley is a completely free reference manager and academic social network that can aid you in organizing your research, collaborate with other academics online, and keep in touch with the latest research [3], [7], [8].

\section{JURN}

According to an article by Educational Technology and Mobile Learning, JURN ranks number 3 in the list of Google Scholar alternatives. They label JURN as a wonderful search engine, that can be used to search for millions of free academic papers, chapters, and theses across multiple disciplines (Arts, History, Humanities, Business, Economics, Ecology, Science etc.) [3], [8], [9].

\section{E. IEEE Xplore Digital Library}

IEEE is considered the world's largest technical professional organization dedicated to advancing technology for the benefit of humanity [8]. It contains material published mainly by the Institute of Electrical and Electronics Engineers (IEEE) and other partner publishers [9], [10].

\section{F. Scopus}

According to its official website, Scopus is the biggest abstract and citation database of peer-reviewed literature: scientific journals, books and conference proceedings. It features an in-depth overview of the world's research output in the areas of science, technology, medicine, social sciences, and arts and humanities. As research becomes increasingly global, spans multiple disciplines and becomes collaborative, you can make sure that critical research from around the globe is not missed when you choose Scopus [3], [6], [8].

\section{G. Microsoft Academic}

Microsoft Academic is a freeware public search engine hosted on the World Wide Web used for academic publications and literature, developed by Microsoft Research, a Microsoft subsidiary. In a similar manner, Microsoft Academic knows titles of journals, names of conferences, and many research topics [8], [10]. This allows software developers to build applications on top of Microsoft Academic, utilizing all of its features [11].

\section{H. ACM Digital Library}

ACM brings together computing educators, research persons, and professionals to inspire dialogue, share knowledge, and address the challenges of the field of research. This secondary database is a rich discovery service known as The ACM Guide to Computing Literature [3], [9], [11].

\section{ResearchGate}

It is known that ResearchGate is a paid social networking web site based in Europe, for scholars and scientists to share publications, ask and answer questions, and pursuit collaborators. Furthermore, a 2016 survey shows that almost as many scholars have registered profiles on the platform Google Scholar [4], [11]. It has been found by a study that over fifty percent of the uploaded papers appear to disobey copyright laws, because the authors have uploaded the edition from the publisher [2], [11].

The main purpose of these sites is in fact the creation of professional communities, where users can build their social networks by connecting to colleagues, finding old connections and creating new links with researchers relevant to their work. Most of these social networks also aim at increasing personal visibility by creating online profiles and sharing work-related contents [4].

In this area, we can identify two main types of instruments: those that were designed for the organisation of research papers, also called reference (or citation) management systems and those that have the primary purpose of providing a showcase for their own publications [4]. The first kind of products arises from the need to gather and organise citations of books and articles that have been identified across research on archives, web sites, library catalogues and OPACs. They are the heirs of the card catalogues used by generations of students, a set of paper cards containing information such as author, title, year and publisher of consulted works. The second category of academic social networks sites is mainly oriented to expose researcher works and facilitate the exchange of personal information. These tools provide simple features to describe researchers' institutional information and interests, promote the uploading and sharing of research documents between members, calculate publication analytics and allow users to post public questions to the community.

After registering on all of these platforms and spending a considerable amount of time on each of them, we made a comparison table which tells us which characteristic each of these platforms excel at, Table 1. [2], [4], [10], [11], [12], [13], [14].

\section{TECHNOLOGIES USED IN THE DEVELOPMENT OF FINKI SCHOLAR}

FINKI Scholar was developed using the latest versions of PHP, Laravel and MySQL. Below is an overview of these technologies.

\section{A. PHP - Hypertext Preprocessor}

PHP: Hypertext Preprocessor, also colloquially known as simply PHP, is a language used for general purpose programming originally designed for development for the web [15], [16]. PHP may be used for many different tasks outside of the context of the web, such as graphical applications and controlling drones remotely.

PHP prides itself in being free and open source. PHP has been ported on many different platforms and can be deployed on most, if not all web servers on almost every operating system and platform, without payment [17]. 
TABLE 1: COMPARISON BETWEEN THE RESEARCH PLATFORMS.

\begin{tabular}{|c|c|c|c|c|c|c|c|c|c|}
\hline & Academia.edu & $\begin{array}{l}\text { Google } \\
\text { Scholar }\end{array}$ & Mendeley & $\begin{array}{c}\text { JUR } \\
\mathbf{N}\end{array}$ & $\begin{array}{c}\text { IEEE } \\
\text { Xplore }\end{array}$ & Scopus & $\begin{array}{l}\text { Microsoft } \\
\text { Academic }\end{array}$ & $\begin{array}{c}\text { ACM } \\
\text { Digital } \\
\text { Library }\end{array}$ & ResearchGate \\
\hline Pricing & $\begin{array}{c}\text { Paid with free } \\
\text { option }\end{array}$ & Free & Free & Free & $\begin{array}{c}\text { Paid } \\
\text { subscription }\end{array}$ & $\begin{array}{c}\text { Paid } \\
\text { subscription }\end{array}$ & $\begin{array}{c}\text { Paid } \\
\text { subscription }\end{array}$ & $\begin{array}{c}\text { Paid } \\
\text { subscription }\end{array}$ & $\begin{array}{c}\text { Paid with free } \\
\text { option }\end{array}$ \\
\hline Open source & No & No & Yes & No & No & No & No & No & No \\
\hline Easy to use & No & Yes & Yes & Yes & No & No & No & Yes & Yes \\
\hline Feature-rich & Yes & Yes & Yes & No & Yes & Yes & No & Yes & Yes \\
\hline $\begin{array}{c}\text { Social } \\
\text { networking }\end{array}$ & Yes & No & Yes & No & No & Yes & No & No & Yes \\
\hline $\begin{array}{c}\text { Multi- } \\
\text { disciplinary }\end{array}$ & Yes & Yes & Yes & Yes & Limited & Yes & Yes & Limited & Yes \\
\hline Trusted & $\mathrm{No}$ & Yes & Yes & Yes & Yes & Yes & Yes & Yes & Yes \\
\hline Collaboration & Yes & Yes & Yes & Yes & Yes & Yes & Yes & Yes & Yes \\
\hline Discovery & Yes & Yes & Yes & Yes & Yes & Yes & Yes & Yes & Yes \\
\hline Interaction & Yes & No & Yes & No & No & Yes & No & No & Yes \\
\hline
\end{tabular}

\section{B. Laravel}

Laravel is one of, if not the most popular of free, opensource PHP web frameworks. Some of the features of Laravel that are listed on its official website are a modular packaging system with a dedicated dependency manager, many different ways for accessing relational databases, utilities that aid in the deployment of applications and their maintenance, and its obsession for syntactic sugar [17], [18], [19].

\section{Blade Templates}

Fully integrated into Laravel, The Blade templating engine is the simple, yet very powerful templating engine that comes with the Laravel framework. According to the official documentation, what it does differently from other popular PHP templating engines is that Blade does not ban you from using plain old PHP code in your views. Blade view files make use of the .blade.php file extension and are usually stored in the resources/views folder [19].

\section{D. $M y S Q L$}

MySQL (usually pronounced "My S-Q-L") is an opensource relational database management system (RDBMS) [20]. MySQL is free (as in free to use and share) and opensource software under the terms of the GNU General Public License, and is also available under several different proprietary licenses [21].

According to many sources, MySQL is utilized by many different database-driven applications on the web, including, but not limited to, Drupal, Joomla, phpBB, and WordPress. MySQL is also utilized by many popular websites, including, but not limited to, Facebook, Twitter, Flickr, and even YouTube [22], [23].

\section{E. jQuery and jQuery Datatables}

According to its official website, jQuery is a library for the JavaScript programming language designed to simplify HTML DOM tree traversal and manipulation, as well as the handling of events, animations based on Cascading Style Sheets, and Ajax requests. It is free (as in free to share), open-source software using the popular and permissive MIT License. According to a different source, web analysis also shows us that it is the most widely used JavaScript library by a huge margin, with 3 to 4 times more uses than any other library for the JavaScript programming language [24]. It provides the users with searching, sorting and pagination functionalities with very little, if any, configuration needed [19], [20], [23].

\section{F. Bootstrap}

Bootstrap is a free and open-source Cascading Style sheets framework directed at front-end development for the web that is responsive and mobile first. It comes with CSSand JavaScript-based element design templates for typography, forms, buttons, navigation and the numerous other elements of the user interface of the application [19], [20], [23], [24].

\section{DeVELOPMENT of the FINKI Scholar Web Application}

During development, the web application was run inside a preconfigured virtual machine called Homestead that came with specific, stable versions of Apache HTTP Server, PHP, and MySQL. The virtual machine was provisioned with a tool called Vagrant. The virtual machine was only used to execute the code, run database queries and return the processed pages. The actual code writing was performed on a Windows host, using the latest version of the Visual Studio Code editor and using the relevant extensions.

\section{A. Database Design}

The database consists of a total of nine tables for and four tables from the framework: titles; locations; journals; journal issues; authors; publications; projects; authors publications; authors projects; migrations; users; password resets.

\section{B. Application Diagrams}

\section{a. Database ER diagram}

The ER diagram was generated from the Data Definition Language by a tool called MySQL Workbench, Fig. 1. MySQL Workbench is a visual database design tool that integrates SQL development, administration, database design, creation and maintenance into a single integrated development environment for the MySQL database system.

b. Use Case diagram

In Fig. 2 you can find the application use case diagram with all of the use cases. It was developed using yEd Graph Editor. 
c. activity diagram for adding a new author

In Fig. 3, you can find an activity diagram for the activity of adding a new author to the system.

\section{d. Class Diagram}

The class diagram was generated from the PHP code itself using the PhpStorm integrated development environment. The diagram includes only classes developed by me and not classes internal to the framework, which explains why there are no relationships between these classes, Fig. 4.

\section{Laravel Database Migrations}

Migrations are like version control for your database, allowing your team to easily modify and share the application's database schema. Migrations are typically paired with the Laravel's schema builder to easily build your application's database schema. If you have ever had to tell a teammate to manually add a column to their local database schema, you've faced the problem that database migrations solve. Using the Laravel migrations you can leverage the framework to intuitively express the given DDL statements in a more programmer-friendly manner. We used the Laravel migrations extensively in the development of FINKI Scholar.

\section{The Design and inner Workings of FINKI Scholar}

The web application consists of a public section, and an administrator panel where administrators can perform administrative tasks.

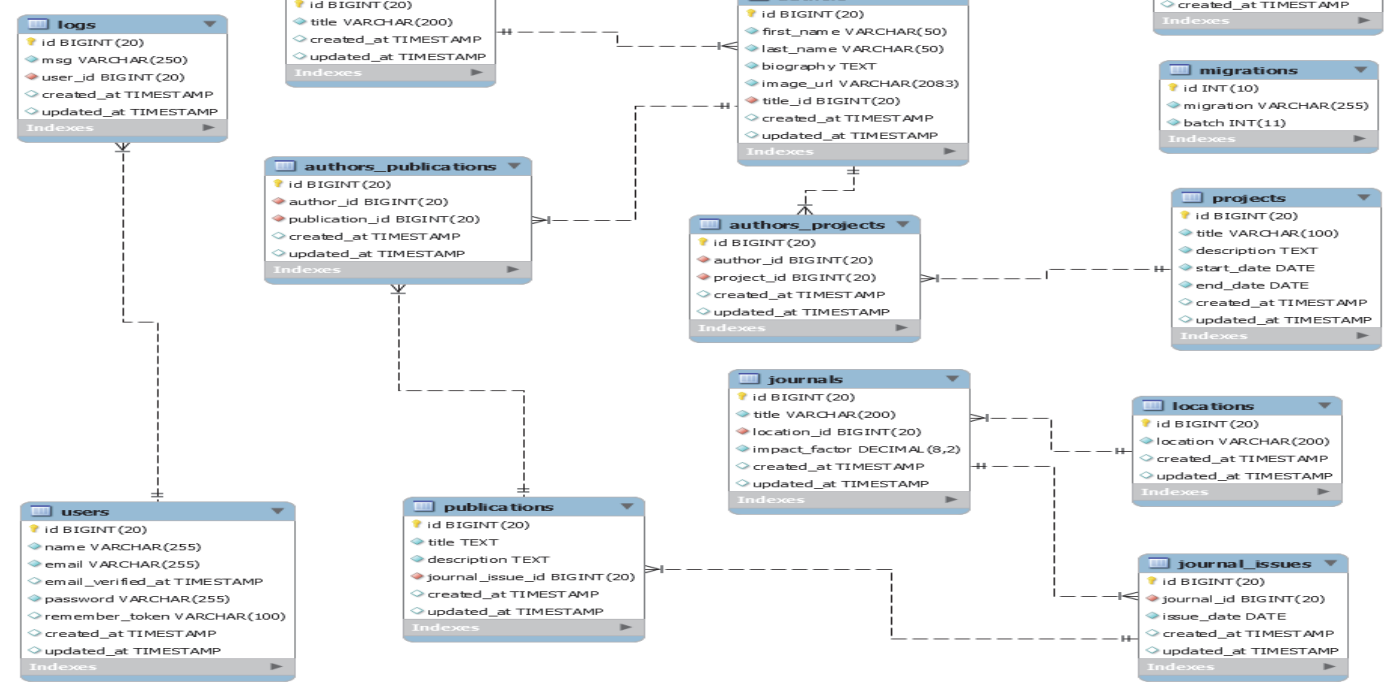

Fig. 1. ER diagram of the FINKI Scholar database.

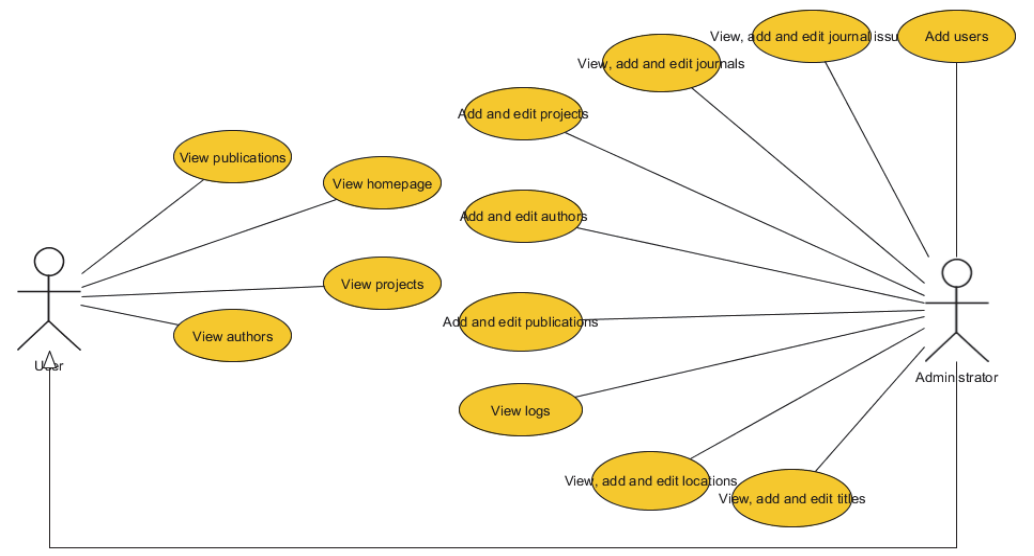

Fig. 2. Application use case diagram.

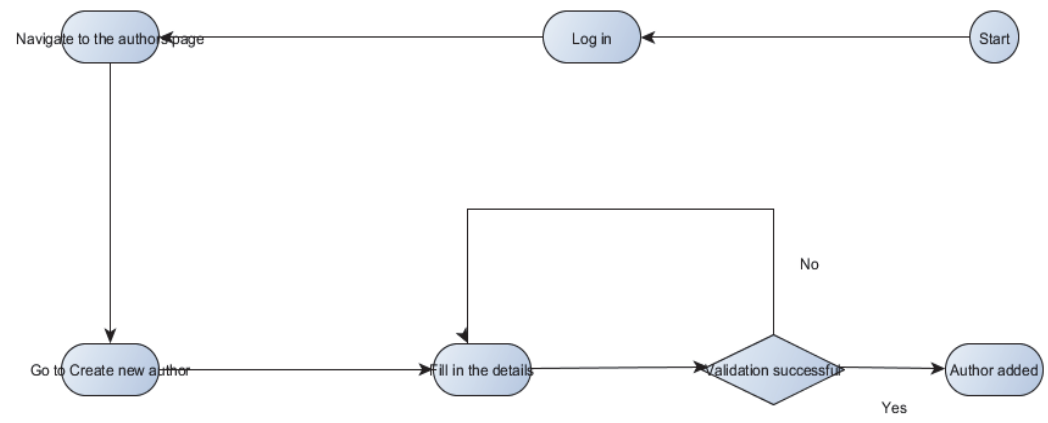

Fig. 3. Activity diagram for adding a new author. 


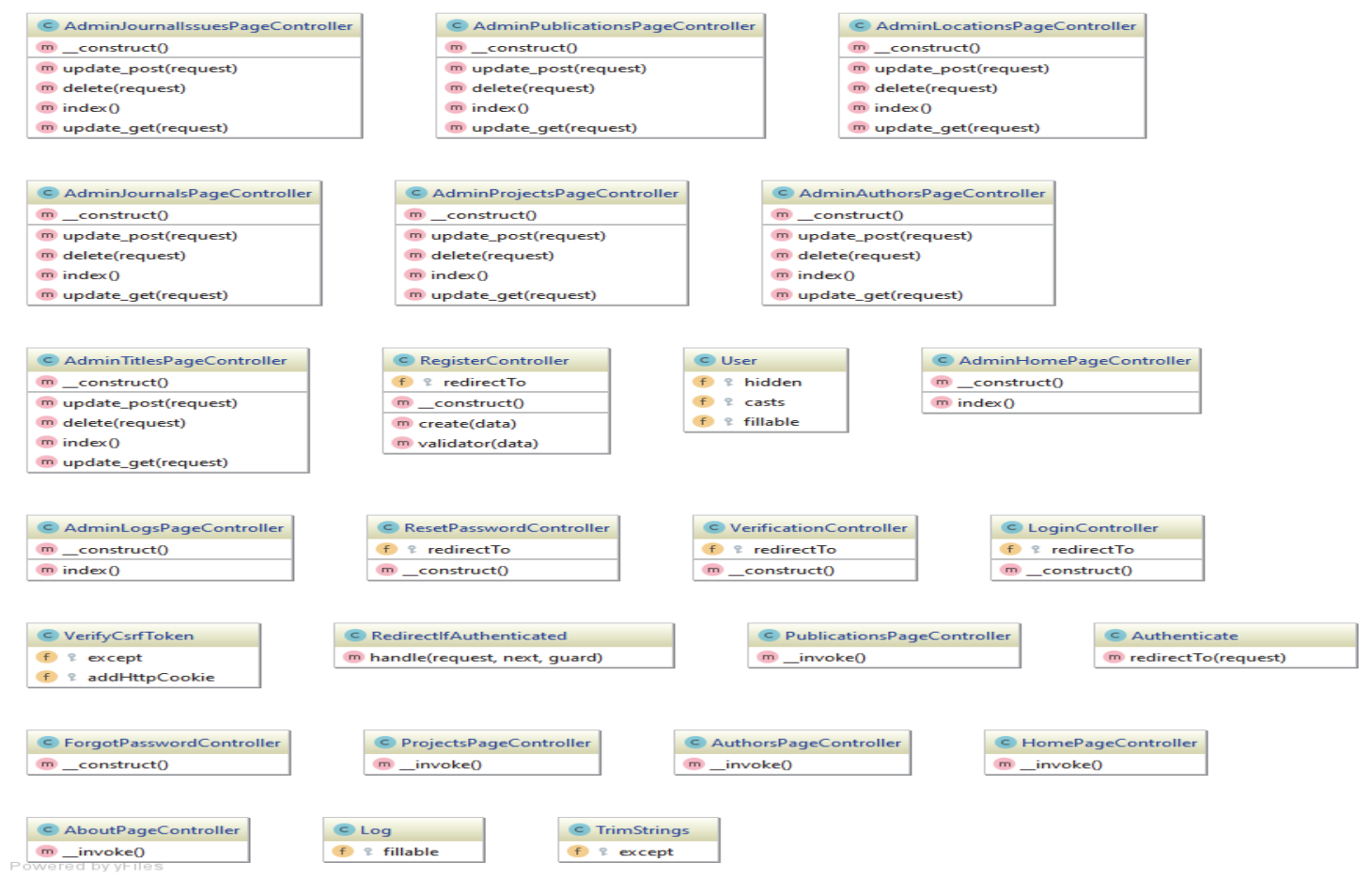

Fig. 4. Application class diagram.

The public section is what the regular website visitors will be able to access. It consists of the following pages: Home page; About page; Authors page; Publications page; Projects page; Login page.

The home page contains static text, basic information about the Faculty of Computer Science and Engineering at the University of Ss. Cyril and Methodius.

The about page contains static text, information about the FINKI Scholar web application and what it intends to accomplish.

The login page allows administrators to authenticate to the administrator panel and get access administrative tasks. The login functionality comes with the framework and is enabled by running php artisan make: auth and adding the following routes entry: Auth::routes();

The authors page returns and displays in an organized manner, all of the authors, including their biography, academic title, and photo, added by the administrators. The biography field is updated to a bootstrap button that opens a modal dialog with the biography of the author.

The projects page returns and displays, in an organized manner, all of the projects, their titles and descriptions, their start and end dates, and all of the authors that have participated in these projects. These projects can be added, modified, and deleted via the administrator panel.

The publications page returns and displays, in an organized manner, all of the publications, their titles and descriptions, the contributing authors, and the journals where these publications have been published.

Visitors have the option to log in and authenticate to the administrator panel. Upon logging in, they will be redirected to the administrator dashboard which contains information about how to get started administrating the database system.

The administrator panel consists of the following pages: Authors administrator page; Projects administrator page;
Publications administrator page; Journals administrator page; Journal issues administrator page; Titles administrator page; Locations administrator page; Logs page; Add administrator page.

The administrator pages display the corresponding entries, and additionally also allow the administrator to update them, delete them, and insert new ones. There are also extra fields shown, such as the time when the entry was created and when it was last modified.

The data tables where the entries are displayed are similar to the ones in the public section, with two additional buttons for updating and deleting the corresponding entries.

The authors administrator page returns and displays in an organized manner, all of the authors, including their biography, academic title, and photo previously added in the system by an administrator.

The projects administrator page returns and displays, in an organized manner, all of the projects, their titles and descriptions, their start and end dates, and all of the authors that have participated in these projects previously added in the system by an administrator.

The publications administrator page returns and displays, in an organized manner, all of the publications, their titles and descriptions, the contributing authors, and the journals where these publications have been published previously added in the system by an administrator.

The journals administrator page returns and displays, in an organized manner, all of the journals, their titles, the impact factors, and the locations previously added in the system by an administrator.

The journal issues administrator page returns and displays, in an organized manner, all of the journal issues, their titles, the impact factors of the journals where they are published, the publish date of the issues, and their locations previously added in the system by an administrator.

The titles administrator page returns and displays, in an 
organized manner, all of the titles previously added in the system by an administrator.

The locations administrator page returns and displays, in an organized manner, all of the locations previously added in the system by an administrator.

The logs page displays a data table of all log entries. Every time an administrator performs an administrative action, such as adding a new publication, a log entry is created and added to the system. These logs are permanent and cannot be deleted. from the system.
Authenticated users can also access the Add Administrator page, where they can submit a form to register a new user with administrator privileges. The Add Administrator page is actually part of the framework authentication module and is enabled by running php artisan make:auth and adding the following routes entry: Auth::routes();

The final product is given in Fig. 5 .

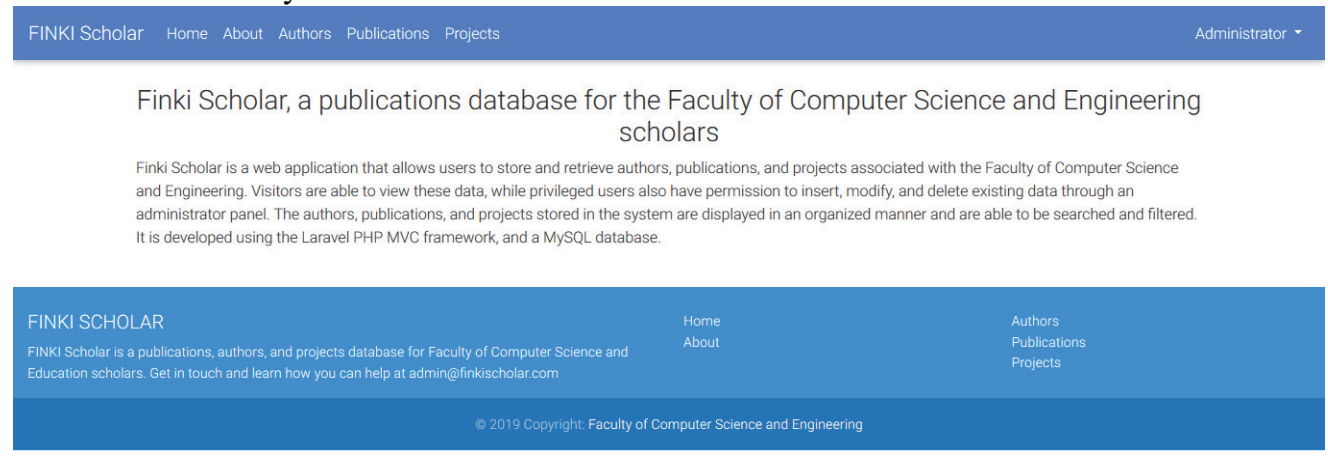

Fig. 5. The FINKI Scholar home page.

\section{CONCLUSION}

In this paper, we successfully implemented the proposed web application for keeping track of the projects and publications of the scholars at the Faculty of Computer Science and Engineering by the University of Ss. Cyril and Methodius. We started off by describing and providing basic information of the technologies we decided to use. We continued by showing and explaining in detail the database structure, graphically and in text. Thirdly, we explained in detail the design and implementation of the actual web application, also providing a sample code where needed to better illustrate the concepts. We finalized the thesis by putting it all together, and showing and demonstrating the features of the final product.

\section{REFERENCES}

[1] Y. Niyazov, C. Vogel, R. Price, B. Lund, D. Judd, A. Akil and M. Shron, "Open access meets discoverability: Citations to articles posted to Academia. Edu," PloS one, vol. 11, no. 2, 2016.

[2] E. Pieterse and H. M. T. Holon, "Academics' use of academic social networking sites: The case of ResearchGate and Academia. Edu." In Proceedings of the European Distance and E-Learning Network 2016 Annual Conference (pp. 18-28), June, 2016.

[3] J. L. Ortega, "Disciplinary differences in the use of academic social networking sites," Online Information Review, Vol 39, no. 4, pp. 520-536, 2015

[4] M. Menéndez, A. De Angeli, and Z. Menestrina, "Exploring the virtual space of academia. In From research to practice in the design of cooperative systems: Results and open challenges" (pp. 49-63). Springer, London, 2012.

[5] J. L. Ortega, "Toward a homogenization of academic social sites: A longitudinal study of profiles in Academia. edu, Google Scholar Citations and ResearchGate." Online Information Review vol. 41, no. 6, pp. 812-825, 2017

[6] A.W. K. Harzing and R. Van der Wal, "Google Scholar as a new source for citation analysis." Ethics in science and environmental politics, vol. 8, no. 1, pp. 61-73, 2008.

[7] J. Bar-Ilan, "Which h-index? - A comparison of WoS, Scopus and Google Scholar." Scientometrics, vol. 74, no. 2, pp. 257-271, 2008.

[8] W. He. D. Jeng and J. Jiang, "User participation in an academic social networking service: A survey of open group users on Mendeley." Journal of the Association for Information Science and Technology, vol. 66, no. 5, pp. 890-904, 2015.
[9] C. P. Hoffmann, C. Lutz and M. Meckel, "Impact factor 2.0: Applying social network analysis to scientific impact assessment." In 2014 47th Hawaii International Conference on System Sciences (pp. 1576-1585). IEEE, (2014, January).

[10] K. Jordan, "Academics and their online networks: Exploring the role of academic social networking sites." First Monday, vol. 19, no. 11, pp. 1-19, 2014.

[11] M. Thelwall and K. Kousha, "Academia. edu: Social network or A cademic Network?." Journal of the Association for information Science and technology, vol. 65, no. 4, pp. 721-731, 2014.

[12] C. Huang, X. Zha, Y. Yan, and Y. Wang, "Understanding the Social Structure of Academic Social Networking Sites: The Case of ResearchGate.” Libri, vol. 69, no. 3, pp. 189-199, 2019.

[13] J. Kinal and Z. Rykiel, "Open Access as a Factor of Enhancing of the Global Information Flow." Procedia - Social and Behavioral Sciences, vol. 83, pp. 156-160, 2013.

[14] K. Jordan, "Academics and their online networks: Exploring the role of academic social networking sites." First Monday, vol. 19, no. 11, 2014.

[15] M. E. Falagas, E. I. Pitsouni, G. A. Malietzis and G. Pappas, "Comparison of PubMed, Scopus, web of science, and Google scholar: strengths and weaknesses." The FASEB journal, vol. 22, no. 2, pp. 338-342, 2008.

[16] M. K. Glass, Y. Le Scouarnec, E. Naramore, G. Mailer, J. Stolz and J. Gerner, Beginning PHP, Apache, MySQL Web Development. John Wiley \& Sons, 2004, pp. 1-40.

[17] X. Yu and C. Yi, "Design and Implementation of the Website Based on PHP \& MYSQL". In 2010 International Conference on EProduct E-Service and E-Entertainment (pp. 1-4). IEEE, (2010, November)

[18] J. Armel, "Web application development with Laravel PHP" Framework version 4, 2014, pp. 30-70.

[19] K. Dockins, Design Patterns in PHP and Laravel. Apress, 2017, pp. 100-140.

[20] M. Stauffer, Laravel: Up \& Running: A Framework for Building Modern PHP Apps. O'Reilly Media, 2019.

[21] S. Suehring and J. Valade, PHP, MySQL, Javascript \& HTML5 allin-one for Dummies. John Wiley \& Sons, 2013.

[22] A. Verma, "Mvc architecture: A comparative study between ruby on rails and laravel." Indian Journal of Computer Science and Engineering (IJCSE), vol. 5, no. 5, pp. 196-198, 2014.

[23] R. Saunier, Getting started with Laravel 4. Packt Publishing Ltd, 2014, pp. 10-30.

[24] В. А. Дронов, Laravel: быстрая разработка динамических Webсайтов на PHP, MySQL, HTML и CSS. БХВ-Петербург, 2018, pp. 30-150.

[25] J. Lockhart, Modern PHP: New features and good practices. " O'Reilly Media, Inc.", 2015, pp. 20-80. 